\title{
Zorrilla, El poeta y el Semanario Pintoresco Español
}

Ricardo de la Fuente Ballesteros

Zorrilla no pudo escapar al éxito del artículo de costumbres en Ignacio Boix recaba su colaboración - un trabajo sobre la figura del "poeta" - para su obra Los españoles pintados por sí mismos. Como senala María de los Ángeles Ayala, el escritor vallisoletano va a seguir la modelización del género, dirigiendo sus palabras al lector, manifestando su satisfacción por el encargo que se le ha hecho, etc., todo ello al uso de las fisiologías francesas, al igual que harán sus colegas participantes en esta colección (Blasco, 231-239). El objeto de este estudio no será una retrospectiva sobre lo que supone la aportación de Zorrilla al género, bien escasa por cierto, sino más bien una lectura de este artículo, dentro del contexto del pensamiento literario de los ańos cuarenta, a la vez que a la luz de la representación que del poeta hace en otros momentos el autor de Don Juan Tenorio, pues se evidencia al comparar este texto con otros que tienen por objeto el mismo personaje que hay una cierta distorsión del mismo. Todo ello contextualizado a través de una de las revistas más significativas del momento: el Semanario Pintoresco.

Tanto al comienzo de su carrera, como al final de la misma, Zorrilla va a darnos una imagen del poeta que participa del modelo 
romántico, de los tópicos de la época. Frente al artista dieciochesco, más profesionalizado y dependiente de su menester y de la sociedad, el romántico tomará su labor como una vocación. Será un ser diferenciado que tendrá poco que ver con el resto de los humanos. El poeta es un vate, un iluminado, un profeta tocado por la mano de Dios. ${ }^{1}$ Esta nueva conciencia de sí mismo hará que, por ejemplo, en los autorretratos que realicen los pintores, los caracteres más determinantes sean la hipersensibilidad, el misterio, la independencia, la seguridad y su marginación del mundo. ${ }^{2}$ Es decir, el poeta es un genio, es un mediador entre Dios y los hombres. Su actividad artística está alejada del oficio para convertirse en algo inherente al sujeto (Henares, 18). El discurso que articulara en este ser especial conllevará el estigma de libertad frente al modelo burgués. ${ }^{3}$ Se desarrolla, pues, una suerte de malditismo que desde entonces no ha abandonado al artista: desde la enfermedad moral a la física, todo sirve para aislar de la masa al individuo por esencia. Ya desde el poema que inaugura las Poesías zorrillescas, "A la memoria desgraciada del joven literato D. Mariano José de Larra”, se da cuenta de este tema:

Que el poeta, en su misión

sobre la tierra que habita,

es una planta de maldita

con frutos de bendición (Zorrilla, vol. 1, 25).

Por otro lado, sobre la alienación de la que hará siempre gala Zorrilla, éste publicará "Cuentos de un loco", en 1858, en El Sema-

${ }^{1}$ Cfr. Rogerd Picard, El romanticismo social, FCE, México, 1987; M.H. Abrams, El espejo y la lámpara. Teoría romántica y tradición crítica, Barral, Barcelona, 1977; Paul Benichou, El tiempo de los profetas. Doctrinas de la época romántica, FCE, México, 1984; R. Argullol, El Héroe y el Único, Destino, Barcelona, 1990.

${ }^{2}$ Cfr. H. Honour, El Romanticismo, Alianza, Madrid, 1986.

${ }^{3}$ La misión del poeta es múltiple: asceta, héroe prometeico, demiurgo o mago, cfr. Sergio Givone, Historia de la estética, Tecnos, Madrid, 1990, 57. 
nario Pintoresco, y en 1867 dará a la imprenta su Álbum de un loco. En "Cuentos de un loco" no podemos dudar de la absoluta seriedad de Zorrilla al considerarse loco por ser poeta y al ofrecernos pedazos de su biografía que anuncian sus Recuerdos del tiempo viejo. Estamos, claro está, en otro de los tópicos románticos: la identificación entre vida y obra. La individualidad todo lo cubre y todo se mide a través de ella. La literatura, la obra artística, rompe con la mimesis y el canon para penetrar la cosa y romper el velo del misterio. Frente a la razón se elevará la imaginación, la intuición y la emoción. La autenticidad de una emoción revela la verdad interna del autor y salva la obra. La experiencia vital individual se configura como el eje ordenador-valorador de la pieza, pero no sólo para el creador, sino también para el receptor. Víctor Hugo lo dejó bien claro:

Le livre est à ce point l'auteur; et le poëme,

Le poëte, notre oeuvre est tellement nous-même,

Nous la sentons en nous si mêlée à nos pleurs,

À notre sang, si bien faite de nos doleurs

Et si profondément dans nos os pénétrante...

En Cuentos de un loco. Episodios de mi vida (1853) podemos leer cómo "Los locos y los poetas no ven las cosas del mundo como los demás hombres". Zorrilla nos ofrece una obra que es

[...] de quien no mora en este mundo

ni con su siglo va ni con su raza, sino de otro universo más poético y más feliz en la región fantástica (vol. 1, 1393).

Son seres incorpóreos los que graban en el cerebro del poeta las historias que él luego narra y

Él las lee en su cerebro de repente

por invisible mano y en palabras

misteriosas escritas, e inspirándose, 
al idioma del hombre las traslada.

¿Quién excitó su inspiración? Se ignora.

Tal vez de origen desigual dimanan:

de Dios, las que a su fe nos aproximan:

de Satán, las que de ella nos apartan (vol. 1, 1394).

El escritor vallisoletano llega a crear la imagen de sí mismo como un ser diferente, dotado de extrañas fuerzas perceptoras. De la misma manera, en sus memorias narra sus fantasías infantiles: la de la imagen de San Martín montado en un caballo blanco -según talla que se encuentra en el altar mayor de la iglesia sobre la misma advocación en la ciudad natal del poeta- que le pareció ver pasar un día por la puerta de su casa y que a la sazón le saluda; o la del episodio referido a su abuela a la que jamás conoció, pero que creyó ver un día sentada en un sillón en el desván de la casa y que, después de los años, reconoce en un cuadro existente en la casa familiar de Torquemada. Ante esto -refiriéndose al primer suceso- comenta Zorrilla:

¿Le vi yo, o no le vi real y positivamente? Si le vi, ¿`cómo pudo efectuarse tan absurda escapada de la imaginería de los altares? Si no le vi, ¿cómo pudo ser tan de bulto aquella visión para conservarla yo como recuerdo de cosa positivamente vista? ¿Es que los niños están más cerca, por no estar aún de él sus almas bien desprendidas, del mundo de los espíritus de donde vienen... o es que esta alucinación era la primera que en mí engendraba el espíritu visionario de mi fantástica poesía? Yo puedo jurar hoy que lo vi; pero es imposible que viera tal imposible. ¿Quién me explica, pues, este fenómeno? (vol. 2, 1860).

En las "Notas" a Los gnomos de la Alhambra (1886), Zorrilla vuelve a la idea de la poesía alejada de la realidad y del don divino:

Nada tan poderoso y fascinador como las ilusiones de los poetas; yo doy a Dios continuamente gracias por haberme dotado de tan vigorosa imaginativa que, desprendiendo mi espíritu del mundo real, me transporta y me hace vivir en la deleitosa región de la poesía, en amenísima sociedad con los seres fantásticos que la pueblan, hijos casi siempre de mis propios recuerdos y de 
los delirios de mis sueños. Yo prefería aquélla al abrigo y al reposo de mi murado aposento los vacíos salones, los desabrigados patios y las solitarias arcadas de la habitación de verano de los granadinos Monarcas; y huyendo de los fantasmas por mis nerviosos terrores abortados, me complací en arriesgarme a tropezar con las tristes sombras de la enamorada Moraima, de la severa Aixa y del desventurado Abd-abdil-al-Zogoibí, quien acaso vuelva alguna vez a su perdido Alcázar cruzando el estrecho en el vacío de la estela de aire que abren las golondrinas, que ya empezaban por aquel entonces a labrar sus nidos en sus descascarilladas torres y desmantelados paredones. - ¿Quién sabe? -¿No es creencia universal de todos los pueblos y de todas las religiones que las almas de los muertos vagan alguna vez por las mansiones de los vivos? (vol. 2, 377).

Léanse estos versos pertenecientes a "Gloria y orgullo" que selecciono entre otros muchos similares:

De un Dios hechura, como Dios concibo;

tengo aliento de estirpe soberana;

por llegar a gigante enano vivo;

no sé ser hoy y perecer mañana (vol. 1, 356).

El poeta por el mero hecho de serlo está maldito, por ello perdió familia, amor y tuvo que emigrar, según versifica en "A Valladolid":

Nací para cantar; es mi destino.

Por dar al vago viento mis cantares

he perdido familia, amor y hogares,

y crucé, vagabundo peregrino,

sin rumbo y al azar tierras y mares (vol. 2, 487).

Zorrilla es, o quiere ser, un genio, por ello desde la niñez tuvo esas experiencias extrańas, y por ello la enfermedad: en la infancia, el sonambulismo, ${ }^{4}$ de adulto, la epilepsia -el mal sagrado-, que com-

${ }^{4}$ La necesidad romántica de construir un mundo alternativo frente a la realidad social, dominada por la insensibilidad, condujo a buscar en los recuerdos de infancia un refugio al que se quería retornar. Es en la niñez donde se manifiesta la 
batía con altísimas dosis de bromuro. De aquí el malditismo tan cuidadosamente reiterado en su obra asociado al cultivo de la poesía, ya desde la composición dedicada a Larra -como señalé más arriba-, o en sus memorias refiriéndose a sí mismo. Cuando mueren sus padres, por ejemplo, se pregunta:

[...] y otra idea más tremenda envolvió mi espíritu en las tinieblas de otra duda que sumía mi alma en la más íntima desesperación [...] Mis padres mueren [...] sin llamarme en su última hora. ¡Dios me deja sobre la tierra sin el último abrazo y sin la bendición de mis padres! [...] ¿Qué he hecho yo a Dios? ¿Están malditos mis pobres versos? (vol. 2, 1850).

Más adelante insiste en los mismos términos: "Estaba escrito, como dicen los árabes, que el miserable ingenio que Dios me dio no me había de servir más que para mi perdición; mis versos estaban malditos por mi padre y yo comencé a aborrecerlos" (vol. 2, 1877).

Es decir, el artista es el héroe contemporáneo, dotado de facultades más allá de la normalidad, es el genio, la más alta manifestación de lo sublime, expresión de la libertad creadora, exaltación del yo, del sueño, de lo inconsciente. Esta idea desarrollada por Zorrilla, tanto en el inicio como en el final de su carrera, y que está en consonancia con el modelo propuesto por el romanticismo europeo, choca con la modelización que nos ofrece el cuadro de costumbres desarrollado en "El poeta". El objetivo que persigue al escribirlo es: "delinear el tipo de Poeta tal cual existe hoy entre nosotros, sin más introducciones ni preámbulos; y sin meterme en lo que han sido, ni debían ser los Poetas, me ceñiré a lo que son, es decir, a lo que al presente debemos entender en este país por un Poeta" (vol. 2, 2137).

diferencia del artista y lo que será en su madurez; por otro lado, el artista es como un niño, lleno de imaginación y tendencia al juego. Es lo que dice el padre de Zorrilla a su hijo, que siempre le parece un nińo. 
A continuación compara su época con la pasada y reafirma la figura del poeta como fundamental en los años en que escribe su artículo: "El siglo pasado fue esclavo del demonio de la filosofía, y el presente del de la poesía; en aquél, para ser hombre de pro, era preciso filosofar, y en éste, para valer, es forzoso poetizar" (vol. 2, 2137). ${ }^{5}$

De la misma manera nos ofrece un panorama extremadamente optimista a la hora de enjuiciar el comportamiento de la sociedad y el Estado cuando han de recompensar la labor del escritor, primero porque es recibido, no por la clase media que se reía de las bufonadas de los escritores del setecientos, sino por la clase alta; incluso el poeta puede alcanzar cualquier puesto importante en la administración -opinión que va a ser contestada al final de su vida pues debemos recordar todas las penurias por las que tuvo que pasar el poeta a quien se le va a escatimar una pensión: ${ }^{6}$

Entonces la poesía era un adorno secundario en un legista, en un curial o en un clérigo $[\ldots]$ : ahora es una carrera como cualquiera otra que conduce a una posición social decorosa, y aun a destinos honoríficos del Estado, y

${ }^{5}$ Al fin de su vida se produce una inversión de la idea aquí expuesta por el vallisoletano, como señala Luis Fernández Cifuentes, "Zorrilla y la ética de la autobiografía” en J. Blasco, R. de la Fuente y A. Mateos (eds.) pp. 45-55, pues a través de los Recuerdos del tiempo viejo de Zorrilla hay una adecuación a los nuevos tiempos, frente a lo que podríamos llamar el tiempo mítico de la juventud y que coincide con el romanticismo, un tiempo clausurado ya y donde se establece la dicotomía tiempo viejo $=$ poesía, tiempo nuevo $=$ prosa, por lo que habla del travestismo zorrillesco, que se disfraza, se viste con la prosa, el "figurín" que se identifica con la modernidad, una modernidad, además, que se confunde con lo masculino -la prensa era lectura primordialmente destinada a los hombres- frente a la poesía, cuyo destinatario principal era el femenino.

${ }^{6}$ Así, en 1871, se le comisiona para estudiar los archivos españoles en Italia, por lo que se traslada a Roma. En 1882 se le nombra cronista de Valladolid -en 1866 la Diputación Provincial le había designado como cronista honorario de la Provincia-, con sueldo de 15 mil reales, aunque esta subvención se le retirará en 1889. Y una pensión nacional por la que habían luchado Ruiz Zorrilla y Juan 
que produce lo suficiente para vivir sin lujo, pero sin estrechez. Entonces se decía por lo bajo: Yo soy un miserable Poeta; hoy se dice con orgullo: La poesía me ha hecho independiente. Entonces un Poeta excitaba la compasión, o era buscado en las sociedades de la clase media para gozar con sus dichos agudos (vulgo bufonadas), y hoy excita la admiración y el aplauso, y es recibido sin dificultad en las mejores sociedades, donde no le resisten la más esmerada educación, ni el más extremado decoro. Entonces podía aspirar a una plaza de escribiente en las oficinas de un grande, en la mayordomía de alguna colegiata, o en casa de un escribano, si tenía buen carácter de letra; y ahora un tomo de poesías, una buena comedia, un poema bien escrito, introduce a un Poeta en la Secretaría de Estado o de Gobernación, en la Biblioteca Real, o en una legación al extranjero donde al paso que goza el premio de su trabajo y talento, los perfecciona y enriquece con nuevos y necesarios conocimientos (vol. 2, 2138).

Esta opinión se puede conectar con el advenimiento de la nueva sociedad que trae el romanticismo y el nuevo estatus del escritor que puede independizarse económicamente, si bien esta independencia no es absoluta por la sujeción del artista a esos cargos públicos a los que parece que aspira y los que aludía Zorrilla. ${ }^{7} \mathrm{Al}$ fin y a la postre el vallisoletano está metido de hoz y coz dentro del sistema y es lógico que hable con esta satisfacción, lo mismo sucede con otros escritores del momento, como es el caso de Mesonero Romanos, sobre el que Ricardo Navas Ruiz señala: “el escritor burgués y liberal se sentía muy

\footnotetext{
Valera llegará tardíamente, pues en 1893, después de su coronación como poeta nacional en Granada (1889), expira nuestro vate en Madrid, tras una operación para la extirpación de un tumor cerebral. Cfr. para este tema Luis Seco de Lucena Paredes, El poeta José Zorrilla y Granada. Cartas inéditas, Universidad de Granada, Granada, 1974; y M. Sancho y Rodríguez, Crónica de la Coronación de Zorrilla, J.G. Garrido, Granada, 1889.

${ }^{7}$ Como dice Miguel Artola, "[la revolución] modificó sensiblemente las condiciones de la producción literaria haciendo surgir un tipo de escritor que, por primera vez, puede llegar a independizarse económicamente del mecenazgo de los poderosos, adquiriendo con ello tanta libertad cuanto las leyes le permitan". Véase "El gusto burgués y sus manifestaciones artísticas" en Francisco Rico, p. 88.
} 
a gusto en un Estado burgués y liberal. ¿Por qué iba a protestar contra sí mismo? ¿Por qué no colaborar? Una vez más. La protesta vendría de gentes de ideología más avanzada como Ayguals de Izco" (Navas Ruiz, 97s.). En todo caso se deben entender estas indicaciones de Zorrilla sobre la clase alta en el sentido de que la clase media es la que ocupa el lugar de la nobleza y que ha tomado conciencia de su papel en la nueva sociedad, de su ascenso social, particularmente en los ańos cuarenta, como señalan Le Bouill y Botrel: "A nivel subjetivo ello se traduce en la idea de una clase media poderosa material, intelectual y moralmente, desarrollando una función predominante en la sociedad, y con un carácter progresista puesto que ha triunfado sobre el antiguo régimen” (en Rico, 77).

Por la misma senda sigue nuestro autor en el artículo oponiendo el desaliño en el vestir de la anterior generación frente a la elegancia de la suya, y la concordia de camaradas entre los creadores frente a la greña en que se hallaban los escritores setecentistas; llamándose ahora "amigos", "lo cual, si no es adelanto de talento, es adelanto de la educación y hombría de bien” (Zorrilla, vol. 2, 2138). Lo que está en la línea del sentido corporativista que toma este gremio, ellos son los portadores de la cultura, del saber y de la virtud. Pertenecen a la misma clase y tienen la misma visión del mundo. Sus valores se basan en los de la burguesía, de la que van de la mano frente al antiguo régimen; como Susan Kirkpatrick apunta en relación a Larra y Mesonero Romanos, estos vieron en la burguesía "la auténtica nación española" (35). Obtienen un gran prestigio social -como el propio Zorrilla señala antes- y se codean con la aristocracia y las clases adineradas. En sus salones es donde encuentran esos contactos y oportunidades para medrar y asegurarse el "nombramiento". Saben que de ellos depende la formación de las nuevas generaciones y el destino del país. Salas y

\footnotetext{
${ }^{8}$ Robert Marrast se centra en el protagonismo de los escritores en esta sociedad y su conexión con las clases dirigentes, cfr. su libro Espronceda y su tiempo. pp. 567-599.
} 
Quiroga en el primer número de No me olvides y Mesonero Romanos en el texto programático del Semanario Pintoresco $(1836,27)$, lo dejan bien claro. Zorrilla no habla de esta función del escritor en su artículo, pero es lo que está en el ambiente, es la seña de identidad del Semanario Pintoresco, revista de costumbrismo y divulgación científica y cultural, representante del romanticismo moderado, "pequeño burgués" (Cruz Seoane, 232).

De estos malos ejemplos de escritores roídos de miseria y de "relajada conducta" viene el rechazo que los padres de familia hacen por la poesía, ${ }^{9}$ y aquí se introduce él mismo con su huída del solar paterno a Madrid en busca de la fama; pero de esto quiere salvar a los verdaderos poetas y por tanto a sí mismo:

${ }^{9}$ La obsesión paterna es una constante en toda su obra y no hay que insistir demasiado en esto, si bien el artículo se conecta con este asunto y es claro que el posible tono moderado del mismo, subrayando el tema de poeta como estudioso y la utilidad social que este oficio tiene, se sintonizan no sólo con las ideas del momento, sino con la aproximación al padre, algo de lo que Zorrilla es muy consciente o que utiliza como exculpación de su conservadurismo. Para muestra un botón:

"Mi idea fija era hacer famoso el nombre de mi padre, para que éste, volviéndome a abrir sus brazos, me volviera a recibir para morir juntos en nuestra casa solariega de Castilla; única ambición mía y único bien que Dios no ha querido concederme. [...] Y puse mi empeño en probarle que la fama que yo había dado a su apellido, la debía sólo al trabajo y al favor del pueblo, no por haber vendido mi pluma a un partido contrario a sus opiniones".

"Usted era carlista y optó por la emigración: no creí decoro del hijo no ser nada en el Gobierno que no había aceptado el padre; he rechazado todo lo que se me ha ofrecido [...].

"Pero si yo he hecho milagros por usted... Me he hecho aplaudir por la milicia nacional en dramas absolutistas como los del rey Don Pedro y Don Sancho: he hecho leer y comprar mis poesías religiosas a la generación que degolló los frailes, vendió sus conventos y quitó las campanas de las iglesias: he dado un impulso casi reaccionario a la poesía de mi tiempo; no he cantado más que la tradición y el pasado: no he escrito ni una sola letra al progreso ni a los adelantos 
Verdad es que la mayor parte de estos malos ejemplos son debidos no a los verdaderos Poetas, sino a la turba de aficionados a la poesía, que no los imitan en las vigilias, los estudios y los trabajos, sino en las estragadas costumbres que el vulgo les atribuye continuamente: porque hablando en plata, amigo lector, tengo para mí que los aficionados son la polilla del arte a que se aficionan (vol. 2, 2138s.). ${ }^{10}$

Es decir, el poeta no es un producto sólo de la inspiración, de la misma manera que el Semanario Pintoresco defendía la disciplina y el estudio y el rechazo de la inspiración, de nada sirve el don del genio si no se desarrolla con el estudio y el trabajo, y no se encamina a un fin virtuoso y noble. El genio tiene un compromiso con la sociedad y la nación. Así Gil y Carrasco, en su recensión de las Poesías de Espronceda (Semanario Pintoresco, 1840: 221-224), dice: el genio "pertenece a la humanidad y al porvenir" y se debe a ellos. Él mismo, cuando tiene que enjuiciar las Poesías de Zorrilla, apunta lo siguiente: "Por lo demás, la idea de que el talento, cualquiera que sea la bandera

de la revolución, no hay en mis libros ni una sola aspiración al porvenir. Yo me he hecho así famoso, yo, hijo de la revolución, arrastrado por mi carácter hacia el progreso, porque no he tenido más ambición, más objeto, más gloria que parecer hijo de mi padre y probar el respeto en que le tengo" (vol. 2, 1782).

Sobre este tema han abundado muchos de los que se han acercado a estudiar a Zorrilla, yo mismo en mi edición de Don Juan Tenorio (Biblioteca Nueva, Madrid, 2003) hablo de la obsesión paterna, y Anna Caballé al ocuparse de las memorias de Zorrilla dice que son "un caso extremo, y único, de tendencia al autoempequeñecimiento, hasta llegar a la nulificación de sí mismo y de su obra [...] Y no se piense que ello es una estrategia psicológica destinada a conmover al lector, sino que responde a motivaciones más profundas de su personalidad, relacionadas con un complejo de Edipo negativo y mal resuelto en la madurez del escritor", p. 156.

${ }^{10}$ Hay un intento de distinguir entre el genio verdadero y los que no lo tienen. Es lo que llama Ignacio Henares la jerarquización, y pone el ejemplo de Ochoa que diferencia entre "pintor" para el genio y "pintador" para el jornalero, cfr. op. cit., p. 24. 
en que se aliste, tiene una misión privilegiada y bienhechora en la humanidad, es harto más social y fecunda que esas mezquinas rencillas literarias" (Semanario Pintoresco, 1839: 71). Parece que el artículo de Zorrilla sigue algunos de estos asertos. De esta manera rechaza composiciones esproncedianas como "El Verdugo" o "Reo de muerte" porque "pertenecen a la escuela amarga, sardónica y desconsoladora de Byron [...] que menosprecian los consuelos y se ceban en sus dolores" (Semanario Pintoresco, 1840: 223) -es decir, el "romanticismo malo" del que hablaba Lista-. Igualmente el poema de Zorrilla "A una calavera" le molesta, pues "anubla a nuestros ojos el porvenir más dulce, el porvenir de la religión”. La verdadera poesía debe ofrecer consuelo y una esperanza que conduzca al bien: "Y cuenta con que no es esto lo que necesita un siglo de suyo egoísta y frío: consuelos y no sarcasmos ha menester el corazón de los más: esperanzas y no desencantos es lo que nos deben ofrecer, porque la desesperación y la duda son impotentes para todo menos para el mal" (Semanario Pintoresco, 1840: 232). ${ }^{11}$ Este valor de la poesía nos lo explica Henares:

Hay como un restablecimiento de la armonía leibniziana: la defensa de la moral y la religión constituye un correctivo histórico. Este es el soporte del discurso de Blanchet: la educación estética tal como se propone se funda en el binomio luces más religión, una forma de exorcizar el cataclismo revolucionario por parte de la burguesía ochocentista. [...] El proyecto de Blanchet es, pues, el programa cultural equilibrado de la burguesía. ${ }^{12}$

\footnotetext{
${ }^{11}$ Donald Shaw en "El prólogo de Pastor Díaz a las poesías de Zorrilla (1837) contexto y significado" ya señala la importancia de ese prólogo como claro estado de conciencia de la necesidad del papel positivo de la literatura en la sociedad, la necesidad de regeneración nacional a través de la labor del artista, etc. Es decir, lo mismo que estamos comprobando a través de las citas tomadas del Semanario Pintoresco.

${ }^{12}$ Cfr. Henares, op. cit., p. 16.
} 
La religión es una forma de oponerse al siglo pasado (Semanario Pintoresco, 1840: 221), a su materialismo que es hermano del filosofismo ilustrado y extranjero y padre de las disolventes corrientes ultrapirenaicas. ${ }^{13}$ Estos poetas de la desesperación serán atacados por el Semanario. Mesonero se ríe del moderno vate, cultivador del "género espasmódico" que repite hasta la saciedad "la historia del genio no comprendido y la emprende con la sociedad" (Semanario Pintoresco, 1842, 294s.). El anónimo autor del artículo "Reflexiones sobre el teatro y las costumbres actuales" dice: "todos estos pretendidos fastidios de la existencia no se desarrollarían tan funesta y rápidamente si el teatro y la literatura en vez de hacer héroes de sus perpetradores, hubiera dicho a unos: sois unos vanos, a otros sois unos solemnísimos bribones; y a los últimos: sois unos pobres mentecatos" (Semanario Pintoresco, 1838: 802s.).

La misión consoladora del poeta encaja perfectamente en el equilibrado programa de la burguesía de orden que opta por la vía del justo medio en su camino hacia el progreso. Es decir, nada de rebelión ni de ruptura de esquemas, más bien integración en el sistema. ${ }^{14}$

Así es como logra el poeta vallisoletano ser el mejor intérprete de las ideas herderianas disueltas e incorporadas en los debates críticos

${ }^{13}$ Igualmente Henares dice al respecto: "los críticos románticos se imponen la obligación de aclarar que la nueva estética nada tiene que ver con la filosofía del desencanto; prorrogando la crítica antiiluminista de finales del setecientos, no asumirán por su carácter resueltamente social los aspectos patológicos de los stürmmer [sic]: dar cabida al sentimiento no significa caer en la desesperación. [...] la educación estética tal como se propone se funda en el binomio luces más religión, una forma de exorcizar el cataclismo revolucionario por parte de la burguesía ochocentista" (idem.).

${ }^{14}$ Como dice Vicente Llorens en El romanticismo español: "Las leyendas de Zorrilla quizá podría considerarlas el lector como poesía de consuelo, más que por alejarlo de una dolorosa realidad presente, por su aceptación del orden establecido y por su exclusión de la duda religiosa” (431). 
de aquellos años, que se pueden sintetizar en la obsesión nacionalista, en realizar una literatura de corte tradicional anclada en los modelos auriseculares y en el mantenimiento del perfil cristiano de esta producción. Todo ello como forma de oposición al llamado romanticismo "frenético" de corte francés. Ya en 1838, al publicar el segundo volumen de sus Poesías, señala que en la redacción de ese tomo había tenido presentes dos cosas: "la patria en que nací y la religión en que vivo. Español, he buscado en nuestro suelo mis inspiraciones. Cristiano, he creído que mi religión encierra más poesía que el paganismo" (vol. 1, 494). No voy a multiplicar las citas, pero al final de su carrera literaria, en sus Recuerdos, insiste en lo mismo: "mi patria, representada por la sociedad, no ha podido hacer más en España por un poeta, a quien indudablemente estima en más de lo que vale, sólo porque su poesía es la expresión del carácter nacional y de las patrias tradiciones" (vol. 2, 1738). Flitter (202s. y 229) también rastrea la recepción de nuestro escritor en esos años y atendiendo a los juicios de Díaz, Bermúdez de Castro y Gil y Carrasco concluye que para la crítica nuestro poeta representa una forma de lección moral, por su utilización de la religión y de la historia de España, impulsando la regeneración de las costumbres y concluye que la interpretación de estos escritores del hacer de Zorrilla es fruto de "la sobrevivencia y el desarrollo coherente de un historicismo romántico schlegeliano, profundamente cristiano en la inspiración y en la orientación, caracterizado por un idealismo intenso y por la creencia en la potencia de las tradiciones nacionales". ${ }^{15}$

Pero volvamos a nuestro artículo. Prosigue Zorrilla poniendo ejemplos de los que son esos aficionados a los que antes se refería, hasta llegar al retrato del verdadero poeta, en el que no descuella ninguno de los estigmas con los que en otras ocasiones lo ha pintado. Por el contrario, dice:

\footnotetext{
${ }^{15}$ Ibid. 241.
} 
[...] es un individuo de nuestra raza humana, que ve la luz en el lugar que el Sumo Hacedor le destina para nacer, en la aldea o en la corte, en la tierra natal o en el mar, y en medio de una familia noble o plebeya, opulenta o miserable, como todos los demás hombres. Recibe la educación que le dan, $\mathrm{y}$ vive sujeto a todas las vicisitudes de la fortuna, ni más ni menos que el resto de sus hermanos; pero, dotado de corazón fogoso y brillante imaginación, empieza a ver y juzgar las cosas con alguna diferencia de lo que las ve y juzga el común de las gentes (vol. 2, 2140s.).

[El estudio, la lectura] despierta en su imaginación ideas nuevas [...] todo lo que aprendió en el colegio, o a solas con sus libros y escritos [...] viene entonces en su ayuda, [gracias a su esfuerzo y a] un cuarto de hora de buena suerte [...], el muchacho pasa a ser hombre y el estudiante a Poeta. En este día empieza para él una nueva era (vol. 2, 2141).

Es decir, el genio se aburguesa, y como señala Narciso Alonso Cortés refiriéndose al contenido del artículo y como comentario al grabado de Jiménez que acompañaba el mismo: "nos presenta al poeta en la tranquilidad del despacho, con su luenga bata de cordones, como un burgués de los más prosaicos" (309). A pesar de esto y de este ideal mesocrático, a autores tan identificados con el nuevo paradigma como Mesonero, les cuesta apartarse del origen divino del genio que sigue ahí activado, a pesar de los pesares:

[...] aquel don celestial del cielo, don que no es dado a los hombres conceder, y que directamente se recibe de la mano del Omnipotente, don que si fortifica y desenvuelve el estudio, es porque encuentra el germen en la cuna, pero don también que a la par que brinda con noble palma al que sabe dirigirle por el buen sendero, imprime severa responsabilidad sobre el ser privilegiado que poseyéndole desconoce su origen divinal y le tuerce en contra de su noble y primitivo fin (Semanario Pintoresco, 1836: 135).

Es lógico, ya que el artista no quiere que su trabajo se equipare al de cualquier trabajador, así que de alguna manera hay que marcar su espiritualidad, su autonomía artística. 
Este artículo tiene mucho de retrato del propio Zorrilla, de ahí que dedique también un párrafo al género que le había consagrado, además de la lírica:

El teatro es en este siglo el objeto de la ambición del Poeta, porque una obra dramática reporta más gloria y más utilidad que otra alguna, y el joven ha echado cuentas para el porvenir. Éste es el Poeta; el que cuenta con hacer de la poesía su profesión y su ocupación de toda la vida. Ansioso de reputación y del aplauso en su país, canta sus glorias en inspirados poemas, ensalza sus héroes en históricas producciones dramáticas, y celebra o critica en sátiras comedidas las virtudes y ventajas, o los vicios y manías de las costumbres de su sociedad y de su siglo. El público recompensa sus fatigas con los aplausos, y su país le agradece lo que hace por su gloria, en nombre de los héroes que celebra y las hazañas que canta, colocando su nombre entre los nombres que darán honor a su centuria (vol. 2, 2141).

Es decir, de nuevo apunta al nacionalismo -que, por otra parte, es el objetivo del costumbrismo, género que representa el carácter nacional frente al peligro que suponen los cambios revolucionarios que se estaban dando entonces (Escobar, 125) que en estos años, como ya he referido, es el tema fundamental, y que, según García Castañeda (15ss.), al principio de los ańos cuarenta Gil de Zárate, Javier de Burgos ${ }^{16} \mathrm{y}$ otros ingenios propugna un "teatro nacional", cuyos modelos serían nuestros clásicos Calderón, Lope, Tirso, Moreto, etc., abundando en la condenación del romanticismo y en la creación de un teatro puramente español, acomodado a la época actual y modelado sobre el áureo. ${ }^{17}$ En este contexto es significativo también el giro de

\footnotetext{
${ }^{16}$ J. de Burgos, “Discurso tercero sobre el teatro español” en El Panorama (1841), pp. 180-183.

${ }_{17}$ Ya en el estreno de Cada cual con su razón -en el teatro del Príncipe-, Zorrilla, al ser reclamado por el público, dijo: "Señores: yo no sé si mi drama es bueno o malo, pero sé que es español. Soy muy amante de mi país, y nada he querido tomar de los franceses. Mi comedia presenta reminiscencias del teatro antiguo, es verdad, pero repito que la he querido hacer español", véase Narciso Alonso Cortés, op. cit., p. 246. Enrique Gil en reseña de la comedia en el Semanario Pintoresco señala:
} 
la dramaturgia zorrillana con piezas clasicistas como Sancho García (1842), Sofronia (1843) y La copa de marfil (1844), prueba de un cambio de orientación en los gustos en esa década, reflejo de lo que aquí se está mostrando. ${ }^{18}$

"La trama es endeble en comparación de la lozanía de los versos y de los subidos quilates del diálogo, y en cuanto a pensamiento capital que forme su fondo y le dé la debida importancia, no tiene ninguno. Tal vez el autor se haya propuesto vencer todos los obstáculos de este género difícil en detalle y no en conjunto, y quizá en la publicación sucesiva de trabajos análogos y de mérito creciente dé muestras más aventajadas de su propósito: por ahora sólo le diremos que si quiso hacer alarde de su facilidad prodigiosa de versificar y de su cabal conocimiento de la flexibilidad y riqueza de la lengua dramática en su bellísimo diálogo, ha logrado su objeto de manera envidiable. Cuando tan felices disposiciones hay que admirar no son de tanto valor las alabanzas como los estímulos, y aunque a la laboriosidad del señor Zorrilla pudiéramos ahorrárselos muy bien, no dejaremos de decirle que la patria espera mucho de él, y que haría muy mal en defraudarla en esperanzas tan legítimas". En las palabras preliminares de la edición de Cada cual con su razón (editada en 1839) dice Zorrilla: "El autor de Cada cual con su razón no se ha tenido jamás por poeta dramático. Pero indignado al ver nuestra escena nacional invadida por los monstruosos abortos de la elegante corte de Francia, ha buscado en Calderón, en Lope y en Tirso de Molina, recursos y personajes que en nada recuerdan a Hernani y Lucrecia Borja. Y por si de éstas sus creencias literarias se les antojara a sus amigos o a sus detractores señalarle como partidario de escuela alguna, les aconseja que no se cansen en volver a sacar [sic] plaza la ya mohosa cuestión de clasicismo y romanticismo.

"Los clásicos ya verán si en esta comedia están tenidas en cuenta las clásicas exigencias. La acción dura veinticuatro horas; cada personaje no tiene más que un objeto, al que camina sin episodios ni detenciones, y la escena pasa en la casa del Marqués de Vélez.

"Los señores románticos perdonarán que no haya en ella verdugos, esqueletos, anatemas ni asesinatos. Pero aún puede remediarse. Tómese cualquiera la molestia de corregir la escena final, y con que el marqués dé a su hija un verdadero veneno, con que él apure el soberano licor que en el vaso quede, con que el rey dé una buena estocada a don Pedro, y la dueña se tire por el balcón, no restará más que hacer sino avisar a la parroquia de San Sebastián, y pagar a los curas los responsos y a los sepultureros su viaje al cementerio de la puerta de Fuencarral" (vol. 2, 2207).

${ }^{18}$ Dice Ermanno Caldera que "quizás se tratara simplemente del deseo de ampliar su repertorio y dar una prueba de particular virtuosismo" y "Hay que pensar 
[Por lo demás] el Poeta no se distingue en nada del resto de los hombres. Sus costumbres están en armonía con sus afecciones, sus caprichos o sus convicciones, como las de todos los demás. Tal vez (lo que sucede a menudo) sus escritos están en oposición con su carácter; y un hombre, metódico, severo y de buenas costumbres, se complace en pintarnos las escenas más bulliciosas, más cómicas o más desordenadas; al paso que otro alegre, feliz e inconstante, nos retrata al vivo grandes cuadros trágicos y profundas y misteriosas pasiones, en que la virtud y el heroísmo juegan los principales papeles (vol. 2, 2141-2142).

Es decir, nada del "cultivador del género espasmódico", de la obra como prolongación de la vida, nada de aquellos poetas que, según Mesonero, "se entusiasman con su propia contemplación, y a falta de objeto que les inspire en este mundo material de cal y canto, se inspiran por la nada, se abisman en el no ser o se evaporan en la región del infinito" (Semanario Pintoresco, 1842: 294-295). El ideario que se postula en estos momentos es el que el genio tiene la obligación de ayudar a su país, no a través de la contemplación de su yo ni con la falta de fe, sino que la literatura tiene una misión consoladora. Por ello, como se señaló antes, la oposición al siglo anterior, a su materialismo y sus "disolventes corrientes transpirenaicas" (Gil y Carrasco, Semanario Pintoresco, 1840: 221).

que los tiempos habían mudado y la dramaturgia oficial de los ańos cuarenta, además de repudiar el título de romántica, se había alejado bastante de los tonos apasionados de la década anterior". Véase su artículo "Sobre las tragedias clasicistas de los románticos”, p. 130. Según Llorens, la reacción contra el romanticismo y el nacionalismo literarios se dirige contra los dramas de Dumas y de Víctor Hugo, pues de su éxito entre 1835 y 1837 se pasa a que se vean como pasados de moda, y Zorrilla que lo percibe se instala en una imitación del teatro del Siglo de Oro, como reivindicación nacionalista, op. cit., p. 440; y que lleva a un nuevo clasicismo y una vuelta a las unidades. Sobre este último asunto véase mi trabajo "Aspectos de la teatralidad romántica: las comedias de Zorrilla” en Ana Sofía Pérez-Bustamante, Alberto Romero Ferrer y Marieta Cantos Casenave (eds.), pp. 237-251. 
Próximo también al aristocrático Mesonero que en varias ocasiones reflexiona sobre el papel del escritor en la sociedad, y que siempre manifiesta su desdén por aquellos que persiguen participar en la vida política, ${ }^{19}$ Zorrilla dice que éste:

No usa de sus facultades poéticas sino en las ocasiones y asuntos que lo requieren: y jamás emplea sus conceptos en adular al poder, en celebrar la injusticia, ni en favorecer sórdidas ambiciones. Recibe modestamente las recompensas o distinciones con que las academias, las autoridades o los gobiernos premian sus talentos (vol. 2, 2142).

En fin, sigue Zorrilla su exposición, siempre reiterando el asunto de la "recompensa" legítima a la que tiene derecho el poeta, ${ }^{20}$ y cómo éste está expuesto a los dimes y diretes del vulgo que desfigura esta historia, cuando alguno, al conocer personalmente a uno de estos

${ }^{19}$ Llega a decir Mesonero en sus Memorias que salvo él y Zorrilla todos los demás han sido diputados, embajadores, etc. En todo caso, cfr. lo que dice Marrast, $o p$. cit., en torno al protagonismo de los escritores en esta época, pp. 567-599.

${ }^{20}$ Zorrilla, en su ajuste de cuentas consigo mismo, con su pasado, con la historia, en sus Recuerdos del tiempo viejo, regresa al mundo de su niñez, del joven que salta a la fama ante la tumba de Larra, el vate coronado ya viejo como poeta nacional, pero durante toda su vida peleado con el dinero. El mundo de la fantasía y de la imaginación que no termina de conciliarse con la prosaica existencia del que, cuando joven, pensó que esa sociedad en la que tan confortablemente estaba instalado, le retribuiría por su misión. Y siempre el padre, el orden que parece como el culpable de su ineptitud para vivir y aprovecharse, cuando hubiera podido, de ese puesto salvador: "Pero si yo he hecho milagros por usted... Me he hecho aplaudir por la milicia nacional en dramas absolutistas como los del rey Don Pedro y Don Sancho: he hecho leer y comprar mis poesías religiosas a la generación que degolló los frailes, vendió sus conventos y quitó las campanas de las iglesias: he dado un impulso casi reaccionario a la poesía de mi tiempo; no he cantado más que la tradición y el pasado: no he escrito ni una sola letra al progreso ni a los adelantos de la revolución, no hay en mis libros ni una sola aspiración al porvenir. Yo me he hecho así famoso, yo, hijo de la revolución, arrastrado por mi carácter hacia el progreso, porque no he tenido más ambición, más objeto, más gloria que parecer hijo de mi padre y probar el respeto en que le tengo" (vol. 2, 1782). 
hombres, les hace creer que están a su altura: "Pero éste es riesgo que corren todos los hombres que se distinguen en algo, y que le toca al Poeta, no por Poeta, sino por hombre distinguido" (vol. 2, 2142). Pero a la vez que nos presenta al poeta como no especial, sino diferente al igual que otros grandes hombres, no deja de señalar también "su carácter y sus exagerados pensamientos", y finalmente selecciona algunas obras sin nombrar a sus autores, como ejemplo de verdaderos poetas "sus nombres pasarán con sus obras a la posteridad, y no les faltará, tarde o temprano, ni una corona de laurel para su sepultura después de su muerte, ni un admirador durante su vida mientras pueda latir el corazón de J. Zorrilla”. En cualquier caso, y a pesar de que todo este artículo sea un alegato sobre la "normalidad" del escritor y el mostrar que no está al margen de la sociedad (Álvarez Barrientos, 1996: 26), la diferencia está presente, pero también la integración dentro del sistema. No vemos aquí al poeta como creador de nuevas realidades. Como he repetido, estamos en unos años de reacción antirromántica ${ }^{21}$ y para nada aparece el individuo convencido de poseer la verdad poética absoluta, el visionario, ni la moral de excepción de la que hablaba Aranguren (1967). Nada más allá de las costumbres burguesas: disciplina, estudio, el rechazo del momento sublime de la inspiración, pues para nada sirve ésta sin la constancia y el trabajo -tampoco si no se encamina hacia un fin virtuoso y noble-. El genio se debe a la "humanidad y al porvenir" (Gil y Carrasco, Sema-

${ }^{21}$ Cfr. Donald L. Shaw, "La reacción antirromántica en España” en David T. Gies, pp. 242-251. Este autor seńala los ańos que van de 1835 a 1845 como los de esta reacción. Cfr. también su trabajo "La critica del romanticismo spagnolo e la sua evoluzione" en H. Juretschke y E. Caldera (eds.), Romanticismo I. Aspetti e problema del teatro romantico, Università di Genova, Génova, 1981, pp. 127135. Cfr. también el artículo de Richard Cardwell, "The Persistence of Romantic Thought in Spain” Modern Language Review LXV, 1970: 803-812. Asimismo, cfr. Llorens, op. cit., pp. 534-539. 
nario Pintoresco, 1834: 223), y como Fernando de Navarrete dice, al reseñar los Ayes del alma de Campoamor: "Hoy el poeta sin renunciar a sus primeras ideas, las ha engrandecido y las ha perfeccionado, si ayer halagaba a la fantasía, hoy enseña algo a la humanidad, y cumple mejor su deber" (Semanario Pintoresco, 1842: 374).

Estamos, pues, en la senda de los elefantes, se acabó el rapto imaginativo, también el juego, todo es utilidad, cálculo, el totalitarismo del futuro, donde el presente y el deseo quedan arrinconados, la moral y lo institucional dominan. Zorrilla y sus compañeros se autocontemplan dentro del sistema, formando parte del engranaje. Decía Javier Herrero que el costumbrismo puede presentar una impronta inmovilista o progresista, pero siempre es conservador (1989: 210s.). Pero como siempre, la cultura propende al modelo y al antimodelo, y la época romántica no iba a ser una excepción. Lo mismo que al carnaval sucede la cuaresma, a la verdad interior le sucede la normatividad social. Tal vez no hay que hablar de sucesión, sino que cualquier posición genera la contraria, de la misma manera que el costumbrismo apela a la realidad y un poema como el Diablo mundo nos muestra la verdad interior de su creador. En cualquier caso hemos podido ver cómo Zorrilla a la versión romántica tópica del creador rebelde e independiente que, por otro lado no le va a abandonar cuando intente ajustar cuentas consigo mismo, con su pasado, con la historia, en sus Recuerdos del tiempo viejo, opone aquí la de un poeta en consonancia con la nueva representación que promueve el Semanario Pintoresco Español, domesticado y fiel siervo de una comunidad que en todo momento tiene el control.

\section{Bibliografía}

AA.VV., 1996, Romanticismo 6. El costumbrismo romántico, Bulzoni, Roma.

Alonso Cortés, Narciso, 1943, Zorrilla. Su vida y sus obras, Librería Santarén, Valladolid. 
Álvarez Barrientos, Joaquín, 1996, "Costumbrismo y ambiente literario en Los españoles pintados por sí mismos" en Romanticismo 6. El costumbrismo romántico, Bulzoni, Roma.

Aranguren, José Luis, 1967, Moral y sociedad. Introducción a la moral española del siglo XIX, Edicusa, Madrid.

Ayala, María de los Ángeles, 1995, "José Zorrilla y las colecciones costumbristas" en Blasco, J.; R. de la Fuente y A. Mateos (eds.), José Zorrilla: una nueva lectura, Universidad de Valladolid, Valladolid, pp. 231-239.

Blasco, J.; R. de la Fuente y A. Mateos (eds.), 1995, José Zorrilla: una nueva lectura, Universidad de Valladolid, Valladolid.

Boix, Ignacio (ed.), 1843-1844, Los españoles pintados por si mismos, 2 vols., Boix, Madrid.

Caballé, Anna, 1991, "Memorias y autobiografías en España (siglos XIX y XX)” en La autobiografía y sus problemas teóricos, Anthropos, suplemento 29.

Caldera, Ermanno, 1996, "Sobre las tragedias clasicistas de los románticos" en Salinas 10.

Cruz Seoane, M., 1977, Oratoria y periodismo en la España del siglo XIX, Fundación Juan March/ Castalia, Madrid.

Fuente, Ricardo de la, 1995, "Aspectos de la teatralidad romántica: las comedias de Zorrilla" en Pérez Bustamante, Ana Sofía; Alberto Romero Ferrer y Marieta Cantos Casenave (eds.), Historia y crítica del teatro de comedias del siglo XIX: ...Y la burguesía también se divierte, Fundación Muñoz Seca/Ayuntamiento del Puerto de Santa María, El Puerto de Santa María, pp. 237-251.

Escobar, José, 1996 "Costumbrismo: estado de la cuestión” en Romanticismo 6. El costumbrismo romántico, Bulzoni, Roma.

Fernández Cifuentes, Luis. "Zorrilla y la ética de la autobiografía” en Blasco, J.; R. de la Fuente y A. Mateos (eds.), José Zorrilla: una nueva lectura, Universidad de Valladolid, Valladolid, pp. 45-55.

Flitter, Derek, 1995, Teoría y crítica del romanticismo español, Cambridge University Press, Cambridge.

García Castañeda, S., 1971, Las ideas literarias en España entre 1840 y 1850, University of California Press, Berkeley.

Gies, David T. (ed.), 1989, El romanticismo, Taurus, Madrid.

Henares, Ignacio L., 1982, Romanticismo y teoría del arte en España, (colaboración de Juan A. Calatrava), Cátedra, Madrid. 
Herrero, Javier, 1989, "El naranjo romántico: esencia del costumbrismo español" en Gies, David T. (ed.), El romanticismo, Taurus, Madrid.

Kirkpatrick, Susan, 1978, “The ideology of Costumbrismo" en Ideologies and Literatures 2 .

Llorens, Vicente, 1979, El romanticismo español, Castalia, Madrid.

Marrast, Robert, 1974, Espronceda y su tiempo, Crítica, Barcelona.

Navas Ruiz, Ricardo, 1990, El romanticismo, Cátedra, Madrid.

Pérez Bustamante, Ana Sofía; Alberto Romero Ferrer y Marieta Cantos Casenave (eds.), Historia y crítica del teatro de comedias del siglo XIX: ... Y la burguesía también se divierte, Fundación Muñoz Seca/Ayuntamiento del Puerto de Santa María, El Puerto de Santa María, 1995.

Rico, Francisco (dir.), 1982, Historia y crítica de la literatura española, V, Romanticismo, Iris M. Zavala (ed.), Crítica, Barcelona.

Shaw, Donald, 1993, "El prólogo de Pastor Díaz a las poesías de Zorrilla (1837) contexto y significado" en De místicos y mágicos, clásicos y románticos: homenaje a Ermanno Caldera, A. Siciliano Editore, Massina.

Zorrilla, José, 1943, Obras completas, ed. Narciso Alonso Cortés, 2 vols., Librería Santarén, Valladolid. 